\title{
Left Ventricular Function of Concentric Hypertrophied Heart after Chronic Pressure Overload as Studied in the Isolated Canine Heart Preparation
}

\author{
Toshio Nakamura, Teruo Kimura, ${ }^{*}$ Shigeru AraI, ** \\ Masakichi MOTOMIYA, ${ }^{*}$ and Norio SuZUKI*** \\ Department of Physiology 2, Tokai University School of Medicine, \\ Isehara, Kanagawa, 259-11 Japan \\ ${ }^{*}$ Department of Internal Medicine, Research Institute for Chest Diseases \\ and Cancer, Tohoku University, Sendai, Miyagi, 980 Japan \\ **Department of Pathology 1, Yamagata University School of Medicine, \\ Yamagata, Yamagata, 990-23 Japan \\ ***College of Medical Sciences, Tohoku University, Sendai, Miyagi, 980 Japan
}

\begin{abstract}
The function of the pressure-overload left ventricle was studied in relation to the chamber geometry of the isolated canine heart. The occurrence of concentric hypertrophy was confirmed in dogs with aortic constriction 40 weeks after operation. The effect of the concentric hypertrophy on left ventricular function was then studied in five pressure-overload dogs. The end-diastolic pressure of the preparation was preset at $20 \mathrm{mmHg}$. In the pressure-overload ventricle, the end-diastolic volume was smaller by $47 \%(p<0.01)$ and the peak systolic pressure was higher by $24 \%(p<0.01)$ than the control at isovolumic beats. Ejection pressure was controlled by our afterload controlling system at various levels and kept constant during the ejection phase. When ejection pressure was the same, the difference in stroke volume between the experimental and control groups was not significant. In the pressure-overload ventricle, the slope (the reciprocal is $E_{\max }$ ) of the regression line of the end-systolic volume on ejection pressure decreased $(p<0.01)$ to $0.095 \mathrm{ml} / \mathrm{mmHg}$ by $47 \%$ from $0.186 \mathrm{ml} / \mathrm{mmHg}$ in the control. The volume-axis intercept $\left(V_{\mathrm{d}}\right)$ of the line was reduced to $55 \%$ of the control. A decrease in the regression line slope was in linear proportion to the degree of concentric hypertrophy, namely, to the change in chamber geometry. These results indicated that: (1) Despite reduction of the end-diastolic volume, the concentric hypertrophied ventricle showed no reduction in stroke volume at the same level of ejection pressure, because of its improved capability to generate pressure. (2) $E_{\max }$ was dependent on ventricular geometry.
\end{abstract}

Received for publication April 13, 1984

中村俊夫, 木村光男, 荒井 茂, 本宮雅吉, 鈴木典夫 
Key Words: concentric hypertrophy, pressure-overload hypertrophy, ventricular geometry, ventricular function, isobaric contraction.

Sustained pressure-overload on ventricle induces cardiac hypertrophy, whereby two changes are observed from a morphological point of view: myocardial hypertrophy and changes in ventricular geometry, namely, concentric hypertrophy (Arai et al., 1968; DeVereux and ReicheK, 1980; Grant et al., 1965; Grossman, 1980; LINZBACH, 1960). To evaluate the ventricular function in the presence of pressure-overload hypertrophy, it is therefore necessary to examine, 1) whether any change occurs in the contractile state of the hypertrophied myocardium, and 2) how the change in ventricular geometry modifies the ventricular function. Publications up to the present have demonstrated that the contractile state of the hypertrophied myocardium remained unchanged in large animals, when pressureoverload was gradually applied (CARABello et al., 1981; SASAYAMA et al., 1976; Williams and Potter, 1974; Wisenbaugh et al., 1983). On the other hand, several investigators have indicated that concentric hypertrophy which occurred in the pressure-overload heart reduced the wall stress to the level of the normal ventricle and that the occurrence of hypertrophy was the mechanism of adaptation to the increased afterload (Grossman et al., 1975; Strauer, 1979). Little information is available, however, concerning the relationship between chamber geometry and ventricular function in the pressure-overload ventricle.

In an isolated heart preparation from a normal dog, SUGA et al. (1973) observed a linear relationship between end-systolic pressure (ESP) and end-systolic volume (ESV), and stated that its slope, namely $E_{\max }$, is useful in evaluating the contractile state of the ventricle. Several investigators have applied this relationship to assess the contractile behavior not only of the normal but also of the hypertrophied ventricle (Grossman et al., 1977; Sagawa, 1981; Spann et al., 1980). However, there has been little experimental evidence suggesting the validity of the pressurevolume relationship of the ventricle obtained in an isolated preparation of a hypertrophied heart model.

This study was undertaken, therefore, to examine how the occurrence of concentric hypertrophy due to pressure overload modifies the ventricular function. First, pressure-overload hypertrophied left ventricle was induced by coarctation of the aorta in mongrel puppies. Then, the heart was excised, metabolically supported, and the pressure-volume relation in the pressure-overload left ventricle at various ejection pressures was studied by keeping the end-diastolic pressure (EDP) at $20 \mathrm{mmHg}$.

\section{MATERIALS AND METHODS}

Five mongrel puppies (average age $5.7 \pm 0.3$ weeks and average body weight $3.7 \pm 0.8 \mathrm{~kg}$ ) underwent an operation to reduce the diameter of the ascending aorta 
(constriction) by the modified method of O'KANE et al. (1973). The puppies were allowed to grow for an average of 40 weeks before study. These dogs showed no signs of heart failure such as ascites, edema of the limbs, or hydrothorax at the time of the following experiment.

Surgical preparation. The isolated canine heart preparation was metabolically supported by a donor dog. A total of 12 preparations were made from five pressure-overload and seven control canine hearts. Donor dogs and heartexcised dogs were anesthetized with sodium pentobarbital $(30 \mathrm{mg} / \mathrm{kg}$, i.v.). Additional anesthesia was given as required. The chest of the dog was opened under artificial respiration and the heart was isolated. After pericardiotomy, the trunk of the left main coronary artery was dissected and a cotton tie was placed beneath it. The heart was fibrillated with electricity, excised immediately thereafter, and its weight determined. A modified Eckstein's cannula with an internal diameter of 2.5 or $3 \mathrm{~mm}$ was inserted into the trunk of the left main coronary artery and was fixed in position by the cotton tie (ECKSTEIN and RowEN, 1967). Care was taken to avoid compression by the ligature of the septal artery, and patency of the septal artery was confirmed in each preparation when the heart was fixed with formalin at the end of the experiment.

All these procedures were done within $30 \mathrm{sec}$ and reperfusion of the heart with the arterial blood from the donor dog through the cannula was started immediately thereafter. The left atrium was opened and the chordae tendineae were cut. A purse-string was placed around the mitral annulus and an L-shaped connecting acryl tube was fixed. The internal diameter of the connecting tube was $14 \mathrm{~mm}$ and the wall thickness $3 \mathrm{~mm}$. A compliant latex balloon was fixed at one end of the connecting tube and was placed in the left ventricular cavity. The other end of the connecting tube was coupled to an afterload controlling system, which will be described below. The balloon and tube were filled with water to drive the air out.

The free wall of the right ventricle was dissected and the coronary sinus flow was drained. The atrio-ventricular node was destroyed by formalin injection and the left ventricle was paced. A catheter with multiple side holes was introduced into the ventricular cavity through the aortic valve. The cusps of the valve were closed by a suture to prevent systolic protrusion of the balloon. Suction was applied through the catheter to maintain the space between the balloon and the endocardium at a minimum and to drain the Thebesian flow. The heart was kept submerged in a blood bath of $37^{\circ} \mathrm{C}$ to the level of the atrio-ventricular groove (Fig. 1).

The arterial blood from the donor dog was pooled in a reservoir and pumped into a bottle with a Windkessel chamber. With this device, the coronary perfusion pressure could be kept at a constant level and the range of its fluctuation remained within $5 \mathrm{mmHg}$ through a cardiac cycle. The temperature of the arterial blood delivered to the ventricle was regulated at about $37^{\circ} \mathrm{C}$ with a heat 


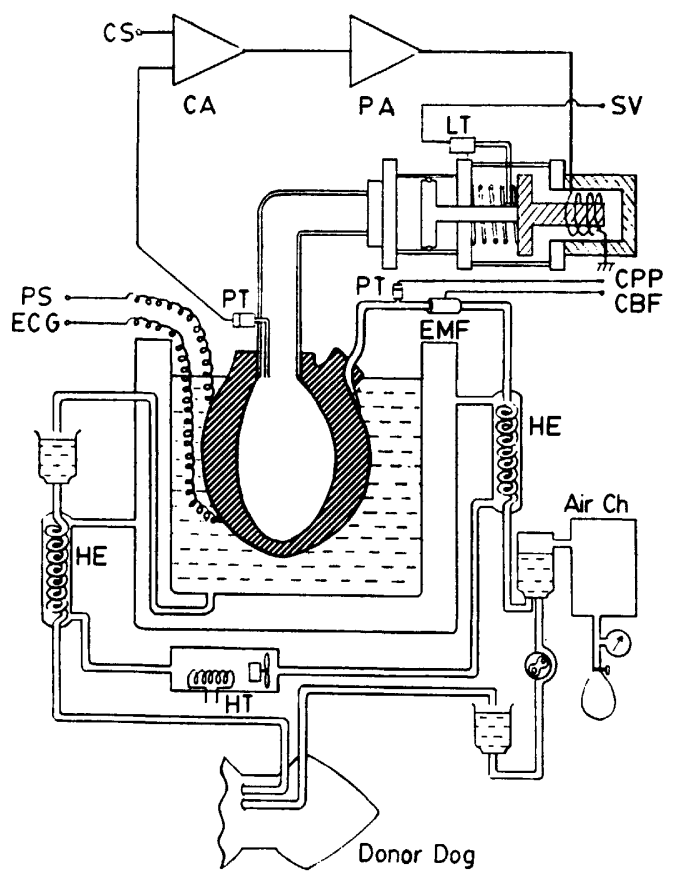

Fig. 1. Schematic illustration of the experimental preparation with an afterload controlling system. Air Ch, air chamber; CA, control amplifier; CS, command signal for the pressure control; ECG, electrocardiogram; EMF, electromagnetic flowmeter; HE, heat exchanger; HT, heater; LT, linear transducer; PA, power amplifier; PS, pacemaker; PT, pressure transducer; SV, stroke volume.

exchanger. After reperfusion, at least $45 \mathrm{~min}$ were allowed for the preparation to stabilize before data collection. The left ventricular pressure was measured by means of a short stainless tube and with a Statham P23Gb transducer. The left ventricular outflow was measured with a linear transducer which was connected to the piston of the afterload controlling system.

Afterload controlling system. The ejection pressure of the preparation was specified at various levels and was kept constant during the ejection phase with the servo-controlled pump system which has been described elsewhere (NAKAMURA et al., 1978). Briefly, the system consisted of a piston in a cylinder $(8 \mathrm{~cm}$ in diameter) actuated by an electromagnet (Matsushita Electric Co. AS-1-0612) and of an electric circuit. The system was operated as follows. The left ventricular pressure (LVP) signal was compared with the pressure command signal of the control amplifier. When the LVP exceeded pressure indicated by the command signal, the difference between the signals was fed to the power amplifier. The left ventricular volume was reduced by the movement of the piston so that the left ventricular ejection pressure was kept at a constant level during the ejection 


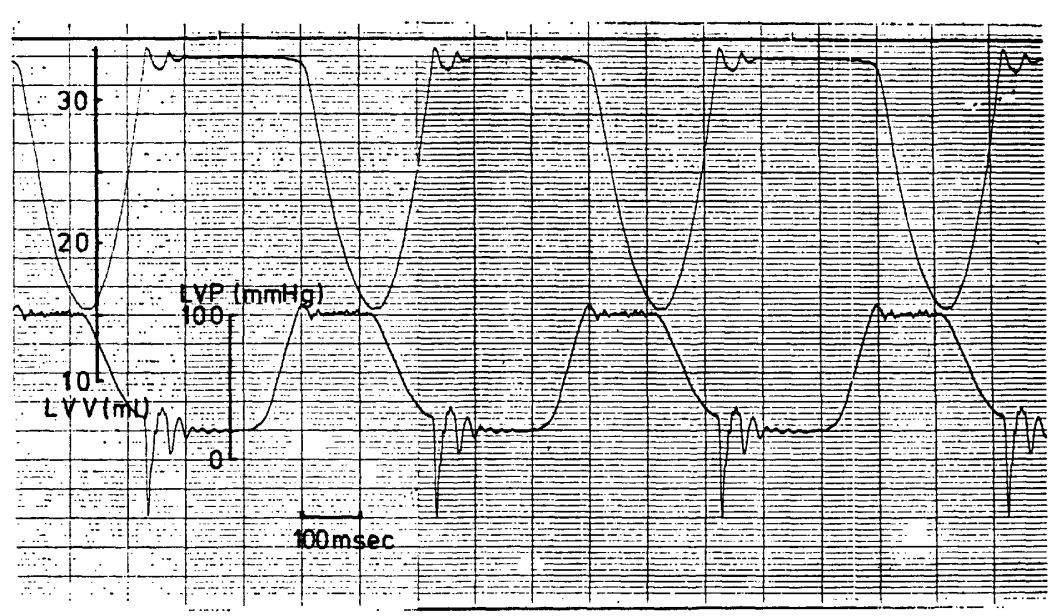

Fig. 2. Tracings of left ventricular pressure and volume at an EDP of $20 \mathrm{mmHg}$ and an ejection pressure of $100 \mathrm{mmHg}$. In this system, the end of ejection is very close to the end of systole. An overshoot at the beginning of the ejection phase does not exceed 10 $\mathrm{mmHg}$. Also considerable irregularities in pressure wave form are observed at the beginning of diastole. They are artifacts caused by a spring coil which is placed in an afterload controlling system. From top to bottom are pacing signal, left ventricular volume (LVV), and left ventricular pressure (LVP).

phase. When the LVP became lower than the pressure of the command signal, the piston returned to the initial position. The EDV was thus kept constant during the experiment.

However, as the electromagnet worked only in one direction, a spring coil was attached to the afterload controlling system in order to return the piston to the initial position (Fig. 1). The volume which was ejected from the ventricle during the ejection phase was returned to the ventricle at diastole with the spring coil. As a result, considerable artifacts were observed at the ventricular pressure wave form at diastole, as shown in Fig. 2. But these artifacts seemed to exert no effect on ventricular function at systole, because $E_{\max }$ in ejection beats was almost the same to that in isovolumic beats in our preparation. In addition, the point where the ejection volume reached its maximum was very close to the point where the ventricular pressure began to decrease from the given ejection pressure in this system.

At the beginning of ejection, an overshoot in ejection pressure (EP) wave form was observed. The overshoot did not exceed the given EP by more than $10 \mathrm{mmHg}$ when the EP was between 60 and $160 \mathrm{mmHg}$, but when the ejection pressure was $40 \mathrm{mmHg}$, it was difficult to keep the overshoot within $10 \mathrm{mmHg}$. In all cases, the EP was successfully controlled within a range of $5 \mathrm{mmHg}$ of a given pressure except at the beginning of ejection. 
Experimental condition and protocol. First, we measured the left ventricular volume $\left(V_{0}\right)$ under an EDP of $0 \mathrm{mmHg}$ in isovolumic beats. Next, the EDVs and the peak systolic pressures at the EDPs of 10 and $20 \mathrm{mmHg}$ were measured in isovolumic beats. Usually, it took 5 to $7 \mathrm{~min}$ for the diastolic pressure of the left ventricle to attain a constant level, after the diastolic pressure was set at 10 or $20 \mathrm{mmHg}$. During this period, a decrease in diastolic pressure was observed. Hence, it was necessary to increase the left ventricular volume slightly to maintain the EDP of 10 or $20 \mathrm{mmHg}$.

The EDP was fixed at $20 \mathrm{mmHg}$ and the EP was reduced stepwise from 160 to $40 \mathrm{mmHg}$ by steps of $20 \mathrm{mmHg}$ with the afterload controlling system while stroke volume was measured. In some ventricles, however, stroke volume at an EP of $160 \mathrm{mmHg}$ was so small that sufficient control of the EP pattern was difficult. In such cases, the stroke volume data at an EP of $160 \mathrm{mmHg}$ was discarded. At the end of the experiments, all heart preparations were fixed at a left ventricular volume of $V_{0}+20 \mathrm{ml}$ with a $10 \%$ formalin solution perfused through the Eckstein's cannula. The balloon was removed, and the left ventricular volume and the weight of the heart were determined. Then the left ventricular weight was measured by FultoN's method (1952). In several cases, the weight of the fixed heart increased within the range of $15 \%$ of the initial weight. In these cases, the left ventricular weight measured at the end of the experiment was corrected according to its weight gain.

The coronary perfusion pressure was kept constant at $100 \mathrm{mmHg}$ and the heart rate at $120 / \mathrm{min}$. The donor dog was ventilated under a positive pressure with room air or supplemental oxygen sufficient to keep blood gases in the physiological range. To maintain a stable contractile state of the isolated heart preparation, the arterial blood gases and serum potassium concentration in the donor dog were carefully monitored and maintained within the physiological range.

Data collection and analysis. We recorded the left ventricular pressure and the stroke volume on an electromagnetic oscillograph with a full scale of $180 \mathrm{mmHg}$ at a paper speed of $200 \mathrm{~mm} / \mathrm{sec}$. All stroke volumes were obtained from steady state conditions under different pressures. It took usually about 2 min for successive beats to become stable after the change in EP. All preparation fulfilled the following criteria of stability: the difference in peak isovolumic pressures was within $10 \mathrm{mmHg}$ before and after ejection runs. In this experiment, preload, namely the EDV, was kept constant and only the afterload was changed. Therefore, the ventricular volume at the end of ejection could be obtained by subtracting the stroke volume at each ejection pressure from the EDV of each ventricle. The afterload was also controlled so that the EP was kept at a constant level during the ejection phase by the afterload controlling system. Therefore in this experiment, the ESP was equal to the EP.

Linear regression was calculated by the method of least squares. When two groups of data were compared, statistical comparison was made using the non- 
Table 1. Body weight, left ventricular weight, and end-diastolic volume of control and pressure-overload dogs.

\begin{tabular}{cccccc}
\hline Dog No. & $\begin{array}{c}\text { BW } \\
(\mathrm{kg})\end{array}$ & $\begin{array}{c}\text { LVW } \\
(\mathrm{g})\end{array}$ & $\begin{array}{c}\text { LVW/BW } \\
(\mathrm{g} / \mathrm{kg})\end{array}$ & $\begin{array}{c}\text { EDV }(10) \\
(\mathrm{ml})\end{array}$ & $\begin{array}{c}\text { EDV (20) } \\
(\mathrm{ml})\end{array}$ \\
\hline Control & & & & & \\
1 & 14.9 & 84.5 & 5.69 & 47.5 & 57.5 \\
2 & 16.2 & 94.9 & 5.86 & 44.5 & 55.5 \\
3 & 16.0 & 87.5 & 5.48 & 47.0 & 57.0 \\
4 & 14.6 & 76.2 & 5.21 & 41.2 & 49.5 \\
5 & 17.0 & 88.3 & 5.20 & 47.8 & 57.5 \\
6 & 14.2 & 74.3 & 5.23 & 48.6 & 57.1 \\
7 & 14.2 & 77.1 & 5.40 & 37.5 & 44.5 \\
Mean & 15.3 & 83.3 & 5.44 & 44.9 & 54.1 \\
S.D. & \pm 1.1 & \pm 7.6 & \pm 0.26 & \pm 4.1 & \pm 5.1 \\
Pressure-overload & & & & & \\
8 & 12.4 & 93.3 & 7.52 & 15.6 & 19.0 \\
9 & 12.1 & 97.1 & 8.02 & 32.6 & 38.7 \\
10 & 11.3 & 118.0 & 10.44 & 35.2 & 42.0 \\
11 & 11.5 & 87.4 & 7.60 & 18.8 & 22.0 \\
12 & 9.0 & 68.5 & 7.61 & 18.9 & 22.3 \\
Mean & 11.3 & 92.9 & 8.24 & 24.2 & 28.8 \\
S.D. & $\pm 1.3^{*}$ & \pm 17.8 & $\pm 1.25^{*}$ & $\pm 9.0^{*}$ & $\pm 10.7^{*}$ \\
\hline
\end{tabular}

BW, body weight; LVW, left ventricular weight; $\mathrm{LVW} / \mathrm{BW}$, left ventricular weight to body weight ratio; EDV (10) and EDV (20), end-diastolic volumes at end-diastolic pressures of 10 and $20 \mathrm{mmHg}$ in isovolumic beats. $* p<0.01$ as compared with controls.

paired Student's $t$-test. Differences at $1 \%$ confidence level were considered significant. All data were expressed as mean \pm S.D.

\section{RESULTS}

The left ventricular weight of the pressure-overload heart of our dogs was not significantly different from that of the control. However, the body weight of the banded dogs was smaller than that of the control. Therefore, there was a significant rise in the ratio of the left ventricular weight to the body weight in the pressure-overload ventricle (Table 1). Thus, the occurrence of left ventricular hypertrophy was confirmed.

The EDV in the pressure-overload heart was significantly smaller than that of the control at EDP of either 10 or $20 \mathrm{mmHg}$. The average diastolic compliance $(0.46 \pm 0.17 \mathrm{ml} / \mathrm{mmHg})$ between EDPs of 10 and $20 \mathrm{mmHg}$ in the pressureoverload heart was significantly lower than that $(0.92 \pm 0.13 \mathrm{ml} / \mathrm{mmHg})$ of the control.

Figure 3 shows the volume/weight ratio of the left ventricle of control and hypertrophied hearts (a), and the peak systolic pressure (b) under an EDP of $20 \mathrm{mmHg}$ in isovolumic beats. These results indicated the occurrence of concentric hyper- 

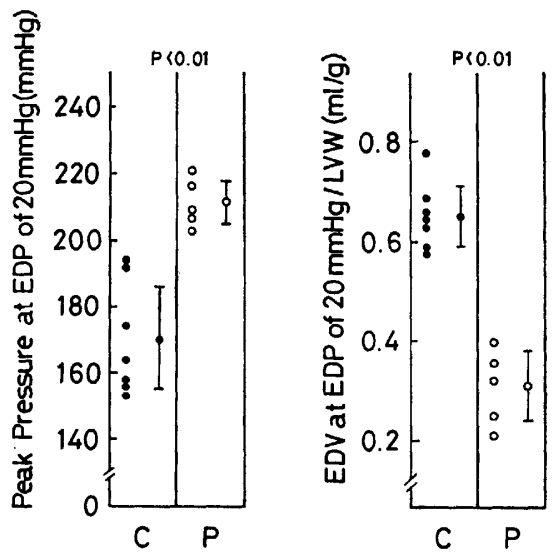

Fig. 3. Ratio of end-diastolic volume at end-diastolic pressure of $20 \mathrm{mmHg}$ to left ventricular weight (a), and peak systolic pressure at an end-diastolic pressure of $20 \mathrm{mmHg}$ at isovolumic beat (b). The occurrence of concentric hypertrophy is indicated by the decrease of volume/weight ratio of the left ventricle. The concentric hypertrophied ventricle generated higher systolic pressure as compared with the control ventricle at the same EDP of $20 \mathrm{mmHg}$.

Table 2. Stroke volume at different ejection pressures of control and pressure-overload heart preparations.

\begin{tabular}{crrrrrrr}
\hline & & \multicolumn{7}{c}{ Ejection pressures $(\mathrm{mmHg})$} \\
\cline { 3 - 8 } Dog No. & 160 & 140 & 120 & 100 & 80 & 60 & 40 \\
\hline Control & & & & & & & \\
1 & 7.0 & 10.1 & 13.4 & 17.2 & 21.0 & 24.2 & 26.2 \\
2 & 6.5 & 10.6 & 14.1 & 17.7 & 20.8 & 23.9 & 27.5 \\
3 & & 10.0 & 15.4 & 19.9 & 24.2 & 27.5 & 31.5 \\
4 & & 5.9 & 10.4 & 13.4 & 16.6 & 19.5 & 22.1 \\
5 & & 8.7 & 11.7 & 16.9 & 21.6 & 25.7 & 27.0 \\
6 & & 3.2 & 8.5 & 12.2 & 17.7 & 22.1 & 27.9 \\
7 & & 3.1 & 7.1 & 11.3 & 14.9 & 18.7 & 22.0 \\
Mean & & 7.4 & 11.5 & 15.5 & 19.5 & 23.1 & 26.3 \\
S.D. & & \pm 3.3 & \pm 3.0 & \pm 3.2 & \pm 3.2 & \pm 3.2 & \pm 3.4 \\
Pressure-overload & & & & & & \\
8 & & 4.8 & 6.3 & 7.7 & 8.9 & 10.6 & 12.4 \\
9 & 12.9 & 14.4 & 16.5 & 18.5 & 21.1 & 23.7 & 26.8 \\
10 & 12.9 & 16.0 & 18.1 & 20.7 & 23.1 & 25.6 & 28.9 \\
11 & 4.1 & 5.7 & 8.1 & 9.0 & 10.5 & 11.4 & 13.6 \\
12 & 2.9 & 5.2 & 7.0 & 8.2 & 9.4 & 10.9 & 12.0 \\
Mean & & 9.2 & 11.2 & 12.8 & 14.6 & 16.4 & 18.7 \\
S.D. & & \pm 5.5 & \pm 5.6 & \pm 6.3 & \pm 6.9 & \pm 7.5 & \pm 8.4 \\
\hline
\end{tabular}

trophy in the hypertrophied hearts induced by constriction of the aorta, and a decrease in diastolic compliance. On the other hand, the pressure-overload 
Table 3. Left ventricular mechanics.

\begin{tabular}{|c|c|c|c|c|}
\hline \multirow[b]{2}{*}{ Dog No. } & \multicolumn{2}{|c|}{ EP-ESV } & \multicolumn{2}{|c|}{ EP-EF } \\
\hline & $\begin{array}{c}\text { Slope } \\
\text { (ml/mmHg) }\end{array}$ & Int (ml) & $\underset{\text { (mmHg) }}{\text { Slope }}$ & Int \\
\hline \multicolumn{5}{|l|}{ Control } \\
\hline 1 & 0.166 & 23.9 & -2.90 & 0.59 \\
\hline 2 & 0.172 & 21.0 & -3.10 & 0.62 \\
\hline 3 & 0.185 & 21.9 & -3.25 & 0.62 \\
\hline 4 & 0.159 & 20.5 & -3.22 & 0.59 \\
\hline 5 & 0.182 & 22.6 & -3.46 & 0.62 \\
\hline 6 & 0.248 & 20.2 & -4.34 & 0.66 \\
\hline 7 & 0.194 & 14.3 & -4.34 & 0.68 \\
\hline Mean & 0.186 & 20.6 & -3.52 & 0.63 \\
\hline S.D. & \pm 0.030 & \pm 3.1 & \pm 0.59 & \pm 0.03 \\
\hline \multicolumn{5}{|c|}{ Pressure-overload } \\
\hline 8 & 0.074 & 3.8 & -3.93 & 0.80 \\
\hline 9 & 0.119 & 7.7 & -3.08 & 0.80 \\
\hline 10 & 0.130 & 8.3 & -3.10 & 0.80 \\
\hline 11 & 0.078 & 5.2 & -3.54 & 0.76 \\
\hline 12 & 0.074 & 7.0 & -3.32 & 0.69 \\
\hline Mean & 0.095 & 6.4 & -3.39 & 0.77 \\
\hline S.D. & $\pm 0.027^{*}$ & $\pm 1.9^{*}$ & \pm 0.35 & $\pm 0.05^{*}$ \\
\hline
\end{tabular}

EP-ESV, relationship between ejection pressure and end-systolic volume; EP-EF, relationship between ejection pressure and ejection fraction; Int, intercept of $Y$ axis of regression line; Slope, slope of regression line. ${ }^{*} p<0.01$ as compared with the controls.

ventricle could generate higher systolic pressure as compared with the control heart, provided that the preload in the ventricle was the same. In other words, the ability to generate pressure of these ventricles was improved.

Table 2 shows the stroke volumes of control and hypertrophied hearts under different EPs. A linear relationship was observed between the EP and the stroke volume in both ventricles. The stroke volume in the pressure-overload ventricle was not significantly different from that of the control at different EPs, despite the fact that the EDV was reduced as the result of the occurrence of concentric hypertrophy. A highly linear correlation between EP and ESV with a correlation coefficient of above 0.98 was found for both control and hypertrophied hearts. The slope of the regression line (the reciprocal of the slope is $E_{\max }$ ) of the relation between EP and ESV of the ventricle, and the volume axis intercept (this corresponds to $V_{\mathrm{d}}$ proposed by SuGA et al., 1973) of the regression line are shown in Table 3. The mean value of the ESV of control and hypertrophied hearts under different EPs and standard deviation are shown in Fig. 4. In hypertrophied hearts, the ESV under different EPs was always smaller than that of the control hearts.

There was a very close correlation between EP and ejection fraction for both control and hypertrophied hearts. Also, it was found that the decrease in ejec- 


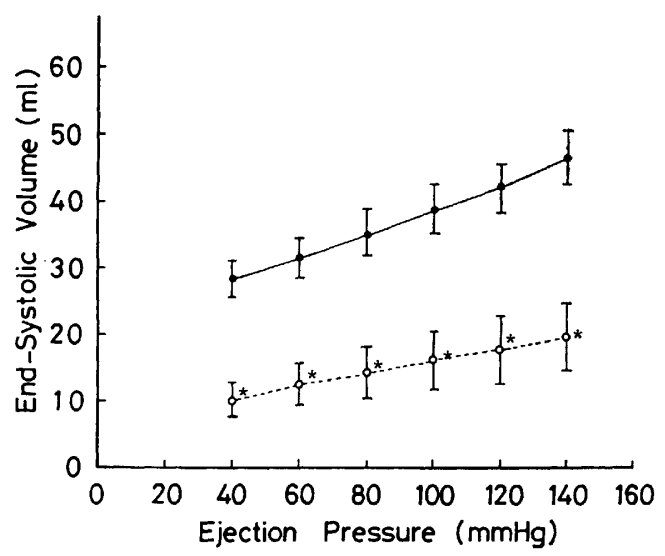

Fig. 4. Average values at six levels of systolic load are plotted for control (solid line) and pressure-overload (dashed line) ventricles. Circles indicate means, and brackets indicate standard deviation.

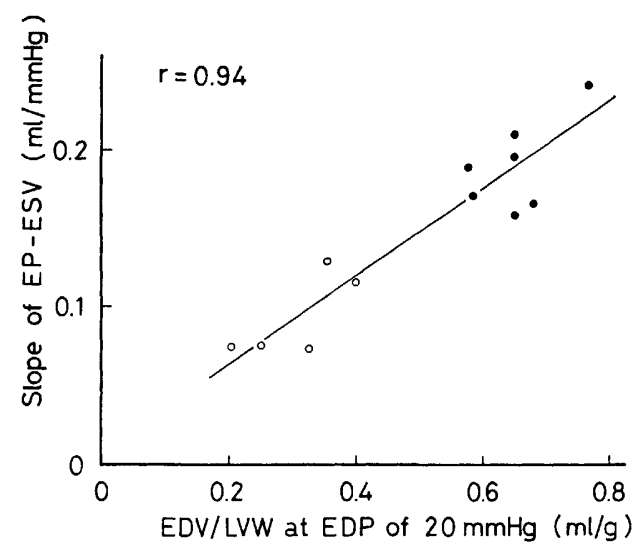

Fig. 5. Relationship between the slope of EP-ESV regression line and the EDV at an EDP of $20 \mathrm{mmHg}$ in control (closed circle) and pressure-overload (open circle) ventricles. A close correlation is found between the slope of EP-ESV regression line and the EDV at an EDP of $20 \mathrm{mmHg}(r=0.94)$.

tion fraction was almost inversely related to EP. The slope of the regression line of ejection fraction on EP in the pressure-overload heart was not significantly different from that of the control. But the intercept of the ejection fraction axis of the regression line was significantly increased as compared with that of the control heart. Thus the ejection fraction was always larger in hypertrophied hearts than in control hearts, when the hearts performed pump action at the same preload and afterload. 
Next, we studied the relation between the ventricular geometry and the slope of the regression line which was obtained on the basis of the relation between EP and ESV. The change of chamber geometry during the process of cardiac hypertrophy was evaluated by using the change in the volume/weight ratio of the left ventricle which was measured under an EDP of $20 \mathrm{mmHg}$ in isovolumic beats. Figure 5 shows the relation between the volume/weight ratio of the left ventricle at an EDP of $20 \mathrm{mmHg}$ and the slope of the EP-ESV relation. The slope of the EP-ESV relation decreased in parallel with the development of concentric hypertrophy. The reciprocal of the slope of the EP-ESV relation is equal to $E_{\max }$. Therefore, the above results indicated that $E_{\max }$ was changed not only by the alteration of the contractile state of the myocardium but also by the change of chamber geometry.

\section{DISCUSSION}

The ventricular function varies according to (1) the loading conditions, namely, the changes in preload and afterload, (2) ventricular size and shape, and (3) the contractile state of the myocardium (BRAUNWALD et al., 1976). Since concentric hypertrophy of the heart and myocardial hypertrophy develop under sustained pressure load, it is conceivable that the above parameters change simultaneously in the pressure-overload ventricle. Taking these problems into consideration, we studied the functional differences between the pressure-overload hypertrophied and control ventricles using the isolated canine heart preparation with their loading conditions set at the same level. The results of this study indicated that the occurrence of concentric hypertrophy in the pressure-overload heart exerted dual effects on ventricular function. The occurrence of concentric hypertrophy increased the ventricular capability to develop pressure and also the ejection fraction and $E_{\max }$, but it decreased the ventricular compliance and as a result, EDV was reduced. Consequently, the stroke volume of the pressure-overload heart was not significantly different from that of the control, when the two heart preparations were investigated at the same EDP and ejection pressure.

Two factors may be responsible for the change in ventricular compliance which was found in the pressure-overload ventricle: (1) change, if any, in compliance of the hypertrophied myocardium and (2) change in chamber geometry. There is still controversy concerning whether any change occurs in the myocardial compliance of the pressure-overload ventricle. Several studies reported that myocardial compliance of the hypertrophied heart was decreased (ALPERT et al., 1974; Bing et al., 1971; Grossman et al., 1974; MirSKy and Pasipoularidos, 1980; SERIZAWA et al., 1982), while others have observed no change in this respect (Grimm et al., 1963; SPANN et al., 1967; GunNing and Colemann, 1973). In our previous studies, the degree of decrease in ventricular compliance was almost proportional to the concentricity of their heart, despite the fact that there was no 
alteration in myocardial compliance (NAKAMURA et al., 1976, 1982). We also showed that stress and strain in the hypertrophied left ventricular wall were smaller than those of the control, when compared at the same EDP (NAKAMURA et al., 1980). These results indicated that the preload on ventricular muscle in concentric hypertrophied ventricle was smaller than in the control at the same EDP.

Because of the decrease in ventricular compliance, the EDV in the pressureoverload ventricle was smaller than that of the control at the same EDP. Despite the decrease in EDV, these ventricles were capable of developing higher isovolumic systolic pressure than the control ventricles, when compared at the same EDP. In other words, the pressure-overload ventricle increased its capability of generating pressure. At the same EDP and EP, the ejection fraction for hypertrophy was larger than that for control. Also $E_{\max }$ was larger in these ventricles. When evaluated by the value of $E_{\max }$ and ejection fraction determined by the experiment, the ventricular function seemed to be improved, but there was no increase in stroke volume due to the concomitant decrease in EDV. Several investigators measured cardiac output, stroke volume, stroke work, peak $\mathrm{d} p / \mathrm{d} t$, and mean $V_{\text {ef }}$ of the pressure-overload heart and reported no functional impairment at rest or during exercise (CARAbello et al., 1981; MaliK et al., 1974; Pfeffer et al., 1976; Sasayama et al., 1976). On the other hand, SaSayama et al. (1977) demonstrated hyperfunction as a pump of these hearts based on the increased wallshortening velocity in comparison with that of the control at a matched level of systolic pressure. Our results indicated that the volume-ejecting ability in these hearts was not increased, despite the increase of the ejection fraction.

In the present study, the left ventricular weight of the pressure-overload dogs was not significantly different from that of the control dogs, because the body weight of the former dogs was smaller than that of the latter. In other words, we matched the left ventricular weight of both groups. On the other hand, almost all the investigators in the previous experimental studies matched the body weight in both groups (CARABEllo et al., 1981; MALIK et al., 1974; WisenBaUGH et al., 1983). Therefore, the left ventricular weight of the pressure-overload animals was larger than that of the controls. These differences may also have contributed to the fact that we observed the results as described above.

It has been proposed by SugA et al. (1973) that $E_{\max }$ may not be affected by the changes in either preload or afterload and may be sensitive to the change in ventricular contractile state. The present study showed that, in the isolated preparation, however, both the slope of the EP-ESV regression line and the volume axis intercept changed in the pressure-overload hypertrophied left ventricle. Since EP was at a constant level during ejection phase, the EP was equal to the ESP and the reciprocal of the slope of the regression line was equivalent to $E_{\max }$. The $E_{\max }$ in the pressure-overload ventricle was $11.18 \pm 2.89 \mathrm{mmHg} / \mathrm{ml}$, an apparent increase as compared with $5.46 \pm 0.73 \mathrm{mmHg} / \mathrm{ml}$ of the control heart $(p<0.01)$. Also we observed a change in chamber geometry of the ventricle, a $52 \%$ reduction 
in average in the volume/weight ratio of the left ventricle. The increase in the slope of the EP-ESV regression line was proportional to the degree of concentric hypertrophy described above. These results indicated that $E_{\max }$ is sensitive not only to the contractile state of the ventricular muscle, but also to the change in chamber geometry.

SAGAwA (1978) pointed out that the value of $E_{\max }$ is related to the subject's body size. He suggested that $E_{\max }$ of the normal human ventricle would have to be half the $E_{\max }$ of the normal canine heart, because the human heart is roughly three to four times as large as the heart of a $20 \mathrm{~kg} \mathrm{dog}$. In our experimental dogs, a $57 \%$ reduction in EDV was found in comparison with that of the control dogs and the value of $E_{\max }$ in the pressure-overload ventricle was almost twice as large as that of the controls. Thus, we must consider the possibility that the increase in $E_{\max }$ was partly due to the reduction of EDV. However, as shown in Fig. 6, there was a close correlation between $E_{\max }$ and the volume/weight ratio of the left ventricle. Therefore, we concluded that the increase in $E_{\max }$ in our pressureoverload ventricles was mainly due to the changes in chamber geometry which resulted from the occurrence of concentric hypertrophy.

In a recent theoretical study, SugA et al. (1984) demonstrated that the product of $E_{\max }$ and $V_{\mathrm{d}}$ was reasonably normalized $E_{\max }$, almost independent of the size of the ventricle and was responsible for the change in myocardial contractility. However, the $E_{\max } V_{\mathrm{d}}(68.3 \pm 15.3 \mathrm{mmHg})$ calculated from our experimental data of Table 3 of the pressure-overload heart was significantly smaller than that (112.3 $\pm 25.7 \mathrm{mmHg})$ of the control ventricle $(p<0.01)$, and these values were sensitive to the change in chamber geometry, namely, to the change in the ratio of EDV at an EDP of $20 \mathrm{mmHg}$ to the left ventricular weight. Therefore, our result indicated that $E_{\max } V_{\mathrm{d}}$ was sensitive not only to myocardial contractility but also to chamber geometry.

The following three possibilities have been reported on the basis of experiments as the causes for the depression of the inotropic state under pressure overload: (1) acute myocardial injury after a sudden increase of pressure load (MeErson, 1965), (2) shift in myocardial isozyme (WiKMAN-Coffelt, et al., 1982), and (3) severe hypertrophy after sustained pressure load (MEERSON, 1965; PFEFFER et al., 1976; SPANN et al., 1967). However, data which are opposed to the above notions have also been published. First, several studies reported that the contractile state of the pressure-overload heart remained unchanged in dogs and pigs, in both of which the pressure-overload was gradually applied in a similar manner as in our study (CARABello et al., 1981; Wisenbaugh et al., 1983). Secondly, a shift in myosin enzyme in the above animals did not seem to occur or was not of physiological significance (LoMPRE et al., 1981; WisENBaUGH et al., 1983). Thirdly, recent studies found no alteration in ventricular function when the gain in the left ventricular mass to body weight ratio was from 25 to $65 \%$ of that of the control (CARabello et al., 1981; Pfeffer et al., 1976; SASAYAMa et al., 1976; 
WiSENBAUGH et al., 1983). In our experiment, the banded animals showed an average of $51.4 \%$ increase in left ventricular mass relative to body weight. As evidenced by the above experimental conditions and results, the myocardial contractile state of the pressure-overload ventricle in this study remained in a physiological range.

The present study has the following problems. First, we measured the left ventricular volume by inserting a compliant balloon into the ventricle. The endsystolic volume was calculated by subtracting the stroke volume from the enddiastolic volume. In the concentric hypertrophied ventricle, it seems difficult to fit the balloon into the ventricle, especially at end-systole, because of the presence of well-developed trabeculae carneae. As a result, there is a possibility that the stroke volume measured experimentally may be slightly larger than the actual stroke volume. Second, we measured the stroke volume of both control and hypertrophied ventricles at the same EDP of $20 \mathrm{mmHg}$. For the control heart, the EDP of $20 \mathrm{mmHg}$ may have been a level a little too high to maintain. At a high EDP, the contractile state of the control ventricle may be less stable. On the other hand, at a low EDP, it cannot eject a sufficient amount of stroke volume under a high ejection pressure of above $120 \mathrm{mmHg}$. In our preliminary experiments, the pressure-volume relation remained linear during isovolumic beats, when the EDP was in the range from 0 to $20 \mathrm{mmHg}$. Therefore, we set the EDP of both ventricles at $20 \mathrm{mmHg}$.

In conclusion, we studied the ventricular function of the pressure-overload hypertrophied left ventricle using the isolated canine heart preparation, with particular attention paid to the effect of altered chamber geometry. The results indicated that in the presence of concentric hypertrophy, there was no increase of volume-ejecting ability of the left ventricle as shown by the values of stroke volume determined under matched EP and EDP. It was found, however, that the capability of the left ventricle to generate pressure was improved.

The authors gratefully acknowledge the advice, criticism, and encouragement of Dr. Haruka Okino. This study was supported in part by a Grant-in-Aid for Scientific Research from the Ministry of Education, Science and Culture of Japan (Project 58570400, 1983).

\section{REFERENCES}

Alpert, N. R., Hamrell, B. B., and Halpern, W. (1974) Mechanical and biochemical correlates of cardiac hypertrophy. Circ. Res. (Suppl. II), 35: 71-82.

Arai, S., Machida, A., and Nakamura, T. (1968) Myocardial structure and vascularization of hypertrophied hearts. Tohoku J. exp. Med., 95: 35-54.

Bing, O. H. L., Matsushita, S., Fanburg, B. L., and Levine, H. J. (1971) Mechanical properties of rat cardiac muscle during experimental hypertrophy. Circ. Res., 28: 234-245.

Braunwald, E., Ross, J., Jr., and Sonnenblick, E. H. (1976) Mechanisms governing the contraction of the whole heart. In: Mechanisms of Contraction of the Normal and Failing Heart, 2nd ed., ed. by Braunwald, E., Ross, J., Jr., and Sonnenblick, E. H. Little Brown and Co., Boston, pp. 92-129. 
Carabello, B. A., Mee, R., Collins, J. J., Jr., Kloner, R. A., Levin, D., and Grossman, W. (1981) Contractile function in chronic gradually developing subcoronary aortic stenosis. Am. J. Physiol., 240: H80-H86.

Devereux, R. B. and Reichek, N. (1980) Left ventricular hypertrophy. Cardiovasc. Rev. Rep., 1 : 55-68.

EcksteIN, R. W. and Rowen, H. E., Jr. (1967) A flexible nonmetalic common left coronary arterial cannula. J. Appl. Physiol., 22: 346-347.

Fulton, R. M., Hutchinson, E. C., and Morgan, J. A. (1952) Ventricular weight in cardiac hypertrophy. Br. Heart J., 14: 413-420.

Grant, C., Green, E. D., and Bunnell, I. L. (1965) Left ventricular enlargement and hypertrophy. Am. J. Med., 39: 895-904.

Grimm, A. F., Kubota, R., and Whitehorn, W. V. (1963) Properties of myocardium in cardiomegaly. Circ. Res., 12: 118-124.

Grossman, W. (1980) Cardiac hypertrophy: Useful adaptation or pathologic process? Am. J. Med., 69: 576-584.

Grossman, W., Braunwald, E., Mann, T., Mclaurin, L. P., and Green, L. H. (1977) Contractile state of the left ventricle in man as evaluated from end-systolic pressure-volume relations. Circulation, 56: 845-852.

Grossman, W., Jones, D., and McLaurin, L. P. (1975) Wall stress and patterns of hypertrophy in the human ventricle. J. Clin. Invest., 56: 56-64.

Grossman, W., Mclaurin, L. P., and Stefadouros, M. A. (1974) Left ventricular stiffness associated with chronic pressure and volume overloads in man. Circ. Res., 35: 793-800.

GunNing, J. F. and ColemanN, H. N. (1973) Myocardial oxygen consumption during experimental hypertrophy and congestive heart failure. J. Mol. Cell. Cardiol., 5: 25-34.

LinzBach, A. J. (1960) Heart failure from the point of view of quantitative anatomy. Am. $J$. Cardiol., 5 : 370-382.

Lompre, A. M., Mercadier, J. J., Wisnewsky, C., Bouveret, P., Pantaloni, C., D'Albis, A., and Schwartz, K. (1981) Species- and age-dependent changes in the relative amounts of cardiac myosin isozymes in mammals. Dev. Biol., 84: 286-290.

Malik, A. B., Abe, T., O'Kane, H. O., and GehA, A. S. (1974) Cardiac performance in ventricular hypertrophy induced by pressure and volume overloading. J. Appl. Physiol., 37: 867874.

MeERson, F. Z. (1965) A mechanism of hypertrophy and wear of the myocardium. Am. J. Cardiol., 15: 755-760.

Mirsky, I. and Pasipoularidos, A. (1980) Elastic properties of normal and hypertrophied cardiac muscle. Fed. Proc., 39: 156-161.

Nakamura, T., Abe, H., Arai, S., Kimura, T., Kushibiki, H., MotomiYa, M., Konno, K., and SuzuKI, N. (1982) The stress-strain relationship of the diastolic cardiac muscle and left ventricular compliance in the pressure-overload canine heart. Jpn. Circ. J., 46: 76-83.

Nakamura, T., Abe, H., Motomiya, M., Kimura, T., and Konno, K. (1980) Stress and strain distribution in diastolic left ventricular wall of the pressure-overloaded hypertrophied heart. Eur. Heart J. (Suppl. A), 1: 174.

Nakamura, T., Asoo, N., Kimura, T., Kosaka, S., Motomiya, M., Konno, K., Suzuki, N., Arai, S., Nakamura, T., and Hashimoto, H. (1978) Development of iso-baric contraction system for the analysis of the ventricular performance. Jpn. J. Med. Electr. Biol. Eng., 16: 126-129 (in Japanese).

Nakamura, T., Nakajima, T., Suzuki, N., Arai, S., and Suwa, N. (1976) Left ventricular stiffness and chamber geometry in the pressure-overloaded hypertrophied heart. Tohoku $J$. exp. Med., 119: 245-256.

O'Kane, H., Geha, A. S., Kleiger, R. E., Abe, T., Salaymeh, M. T., and Malik, A. B. (1973) 
Stable left ventricular hypertrophy in the dog: Experimental production, time course and natural history. J. Cardiovasc. Thorac. Surg., 65: 264-271.

Pfeffer, M. A., Pfeffer, J. M., and Frohlich, E. D. (1976) Pumping ability of the hypertrophying left ventricle of the spontaneously hypertensive rat. Circ. Res., 38: 423-429.

Sagawa, K. (1978) The ventricular pressure-volume diagram revisited. Circ. Res., 43: 677687.

SAGAWA, K. (1981) The end-systolic pressure-volume relation of the ventricle: Definition, modifications and clinical use. Circulation, 63: 1223-1227.

Sasayama, S., Franklin, D., and Ross, J., Jr. (1977) Hyperfunction with normal inotropic state of the hypertrophied left ventricle. Am. J. Physiol., 232: H418-H425.

Sasayama, S., Ross, J., Jr., Franklin, D., Bloor, C. M., Bishop, S., and Dilley, R. B. (1976) Adaptations of the left ventricle to chronic pressure overload. Circ. Res., 38: 172-178.

Serizawa, T., Mirsky, I., Carabello, B. A., and Grossman, W. (1982) Diastolic myocardial stiffness in gradually developing left ventricular hypertrophy in dog. Am. J. Physiol., 242: H633-H637.

Spann, J. F., Bove, A. A., Natarajan, G., and Kreulen, T. (1980) Ventricular performance, pump function and compensatory mechanisms in patients with aortic stenosis. Circulation, 62: $576-582$.

Spann, J. F., Jr., Buccino, R. A., Sonnenblick, E. H., and Braunwald, E. (1967) Contractile state of cardiac muscle obtained from cats with experimentally produced ventricular hypertrophy and heart failure. Circ. Res., $21: 341-354$.

STRAUER, B. (1979) Myocardial oxygen consumption in chronic heart disease: Role of wall stress, hypertrophy and coronary reserve. Am. J. Cardiol., 44: 731-740.

Suga, H., Hisano, R., Goto, Y., and Yamada, O. (1984) Normalization of end-systolic pressurevolume relation and $E_{\max }$ of different sized hearts. Jpn. Circ. J., 48: 136-143.

Suga, H., Sagawa, K., and Schoukas, A. A. (1973) Load independence of the instantaneous pressure-volume ratio of the canine left ventricle and effect of epinephrine and heart rate on the ratio. Circ. Res., 32: 314-322.

Wikman-Coffelt, J., Parmley, W. W., and Mason, D. T. (1982) Relation of myosin isozymes to the heart as a pump. Am. Heart J., 103: 934-940.

Williams, J. F., Jr. and PotTeR, R. D. (1974) Normal contractile state of hypertrophied myocardium after pulmonary artery constriction in the cat. J. Clin. Invest., 54: 1266-1272.

Wisenbaugh, T., Allen, P., Cooper, G., IV, Holzgrefe, H., Beller, G., and Carabello, B. (1983) Contractile function, myosin ATPase activity and isozymes in the hypertrophied pig left ventricle after a chronic progressive pressure overload. Circ. Res., 53: 332-413. 